\title{
A Reforma Administrativa e os Sistemas de Contrôle
}

\author{
REINHOLD STEPHANES \\ Economista - Inspetor-Geral de \\ Finanças do Ministério \\ da Agricultura
}

NORIVAL ONOFRE KWIATKOWSKI

Economista - Div. Adm.

Financeira - MA

\section{INTRODUÇÃO}

O presente estudo pretende demonstrar a inadequação dos meios de ação postos à disposição dos executores das funções de govêrno e os seus reflexos na gerência dos gastos públicos, pondo em relêvo alguns aspectos importantes nessa fase de transição que caracteriza a implantação da Reforma Administrativa. Pretende, também, levantar alguns subsídios para a formulação de diretrizes e normas básicas de ação, a fim de superar as naturais dificuldades encontradas nessa fase excepcional, inerentes à implantação de qualquer reforma.

Os mecanismos de contrôle postos em prática a partir do exercício de 1968 , estão evidenciando erros que se vinham repetindo, ano após ano, por falta de uma sistemática capaz de constatá-los e medir-lhes a profundidade a tempo de permitir a sua correção.

Foi grave mesmo, dentro do natural processo de evolução sócio-econômica do País, a ausência de um sistema de contrôle efetivo e eficiente na administração pública, o que permitiu a acumulação de erros e vícios em escalas hoje imensuráveis.

Vale aqui reproduzirmos as palavras do Ministro Iberê Gilson, do Tribunal de Contas da União, que, em seu parecer prévio sôbre as contas do Govêrno no exercício de 1966, diz: "As modificaçốes da conjuntura administrativa; a ampliação das atividades estatais a áreas cada vez mais extensas onde até pouco atuava tão-sòmente a atividade privada; 0 acentuado $e$ indesmentível desenvolvimento econômico e social que tem expe- rimentado o Brasil; a inadequação das regras vigentes à administração pública; e a redução do âmbito do contrôle prévio dêste Tribunal - pela expedição de uma legislação desmetodizada - sem transferi-lo a outros órgãos, tudo isso conduziu - Poder Público a uma quase absoluta carência de contrôle. Dentro de tal ordem de idéias, Alfredo Wetternick assim expressou seu pensamento: “... uma organização adequada, de modo geral, deve ser a resultante das contínuas inovações impostas pelo natural processo de evolução constante".

Com o advento do Decreto-lei número $200 / 67$, e diante da defasagem existente entre a conceituação dos objetivos e a realidade da administração pública brasileira, os mecanismos de contrôle instituídos esbarram, já de princípio, em práticas administrativas eivadas de vícios, porém sedimentadas pela prática constante, principalmente no campo da execução financeira.

Assim sendo, ter-se-á que utilizar os atuais sistemas de contrôle, conforme ficará evidenciado na análise a seguir, bàsicamente como instrumentos corretivos e preventivos através de orientação integral das atividades-meio, evitando-se que se criem traumas na execução das funções do Govêrno, capazes de gerar sérios problemas para a dinamização administrativa que se está efetivando no País.

O importante nesta primeira fase de implantação dos atuais sistemas de contrôle é o estabelecimento de princípios de análise sôbre a administraçẫo em geral, principalmente a financeira, o que facultará valiosos subsídios para a ela- 
boração de uma estratégia de açâo integrada para a correção dos vícios e erros, com a aplicação de medidas punitivas nos casos comprovadamente dolosos, cumprindo-se, por etapas, as necessárias reiormulaçôes de atitudes e hábitos a fim de forjar uma mentalidade consciente e atuante no serviço público. P'ois em sua ausência, muito mais do que simples modificações de estruturas formais, organogramas e fluxogramas a Reforma Administrativa importa em uma reformulação de mentalidade de pontos de vista e de modos de ser.

A Reforma Administrativa no Brasil não é tema recente. No momento ela alcança uma evidência sem precedentes, no esfôrço de reduzir o descompasso entre a capacidade operacional da máquina administrativa e as crescentes exigências do desenvolvimento econômico e social, graças a um estado institucional singular apoiado por uma firme e objetiva atitude de Govêrno.

Em administração é admitido como axioma não existir tarefa que não possa ter melhorado seu grau de racionalidade, simplicidade ou produtividade com base nas variações ambienciais e tecnológicas. Êsse axioma é observado na prática pela emprêsa privada, que tem em sua consecução, inclusive, envolvida sua própria sobrevivência e prosperidade.

\section{ESSA ADAPTAÇÃO \\ E NECESSARIAMENTE UM \\ PROCESSO CONTINUO}

A administração pública brasileira não acompanhou de maneira satisfatória a evolução constatada, tanto no campo administrativo pròpriamente dito como na conceituação das funções de Govêrno. Em nível governamental, essas conceituações sofreram mudanças profundas, principalmente em função das doutrinas econômicas surgidas após as crises mundiais de 1929 e da Segunda Guerra, que repercutiram em todos os setores das atividades humanas. À medida que os novos conceitos eram assimilados, impunha-se como essencial uma eficiente adaptação do instrumental técnico, legal e administrativo às novas concepções desenvolvimentistas, o que não ocorreu. Dessa forma, foi se agravando a um grau sem precedentes, a inadequação dos instrumentos de trabalho disponiveis, incluídos aqui os institucionais, aos objetivos de Govêrno e gerando, em escala cada vez maior, um descompasso entre a capacidade operacional e as exigências do desenvolvimento nacional.

A adaptação dos meios aos objetivos, devido à enorme defasagem observada, não mais poderia ser alcançada por processos naturais ou graduais, evidenciando-se a necessidade de uma mudança profunda e rápida nos conceitos e métodos.

Podemos, nesse ponto, evidenciar duas premissas da reforma administrativa:

E um processo geral, objetivando elevar a racionalidade e funcionalidade da administração pública a niveis compatíveis com as suas atribuições.

Não é um processo final, mas um tratamento destinado a adaptar, a médio prazo, o aparelho administrativo, às funções a que se destina e permitir que, a partir dêsse momento, as necessárias mutações, decorrentes da evolução, possam ser processadas gradativamente.

Nestas premissas reside a nossa maior preocupação, sendo o enfoque principal para os fatos que desejamos demonstrar com êste trabalho.

O progresso social e tecnológico da humanidade se tem efetuado com uma rapidez impressionante, e, em certos setores, de maneira dificilmente previsivel. Em têrmos de comparação, a sociedade humana, nos últimos 50 anos, evoluiu mais que em tôda a sua existência histórica. E essa evolução contínua, em processo aceleratório, traz consigo a necessidade de constantes mudanças e aperfeiçoamentos das funções de Govêrno e de seu instrumental.

Nesse contexto, o esfôrço de adaptação do aparelho administrativo, a médio prazo, teria que se dar numa verdadeira corrida contra o tempo. Mesmo assim, se se conseguisse aproximar do ponto de equilíbrio entre o processo da evolução social e econômica, e o processo evolutivo da administração pública, ainda teríamos que estabelecer mecanismos que permitissem o acompanhamento do processo aceleratório.

Uma das fases do processo desencadeante da reforma da administração pública brasileira se deu com a sua institucionalização, através do Decreto-lei n. ${ }^{\circ} 20 u / 67$. Este documento mantém sua validade como instrumento normal-doutrinário e conceitual, capaz de deflagrar o processo global de reforma dentro do enfoque exposto. 
Devemos, porém, enfatizar que o Decreto-lei n..$^{\circ}$ 200/67 é o princípio de um processo e não o seu coroamento.

Particularmente, no campo financeiro, a reformulação visou a sistematizar e dar consistência ao fluxo financeiro e ao seu contrôle, como demonstra a institucionalização dos sistemas de Administração Financeira, Contabilidade e Auditoria. A nosso ver, a concepção válida para o atingimento dos objetivos da Reforma é a de equacionar e estruturar as atividades-meio, para que sirvam de efetivo suporte às atividades-fim, dentro de princípios de adequação recíproca.

Propomo-nos, nesse ponto, a um rápido diagnóstico da situação, particularizando no enfoque os órgãos da Administração direta do Ministério da Agricultura. Tal enfoque não impede, porém, talvez com raras exceções, a generalização das constatações.

O Ministério da Agricultura conta com cêrca de 35.000 servidores, distribuídos por mais de 2.000 bases físicas, espalhadas pelo território nacional. Dessa maneira, face à expressão continental do País, a rêde executiva sofre o impacto das mais variadas condicionantes, como sejam:

- deficiência de transportes e comunicações, acarretando dificuldades de acesso do fluxo financeiro e ao de informações e contrôle;

- condições sóci io-econômicas, ambientais e estruturais, envolvendo todos os vícios e erros sedimentados na administração pública;

- fatôres sazonais, uma das principais condicionantes a que está sujeita a agricultura.

Sôbre êste quadro, a Inspetoria-Geral de Finanças do Ministério da Agricultura, baseada na sua posição de órgão suporte das atividades-fim, montou os seus sistemas de acôrdo com as normas preconizadas pelo Decreto-lei n. ${ }^{\circ} 200$, de 1967, e Decretos n. ${ }^{\circ}$ s $61.386 / 67$ e 62.102 , de 1968.

Dentro de uma visão global da problemática administrativa, os sistemas foram equacionados de forma a dotar o fluxo financeiro de automaticidade, flexibilidade e rapidez necessários ao bom desempenho dos encargos atinentes aos órgãos do Ministério e, paralelamente, estabelecer um eficiente sistema de acompanhamento e contrôle, baseado num fluxo de informações simples e objetivas, complementado pelos sistemas de análise e auditoria.

É significativo destacar, após um ano de funcionamento na nova sistemática, as seguintes apreciações:

a) demonstrou sua adequação e viabilidade, pois que está conseguindo pôr em prática os pressupostos básicos da reforma administrativa, preconizados pelo Decreto-lei n. 200/67;

b) ela permitiu a introdução da programação financeira em têrmos de ajustamento dos fluxos financeiros à execução técnica. É que, com o critério programático, levouse em consideração, também, a fixação de critérios de prioridade conforme as exigências técnicas de cada projeto a executar;

c) os erros e vícios constatados não foram resultantes da nova sistemática; ocorreu que os novos padrões introduzidos em têrmos de acompanhamento e contrôle é que permitiram localizá-los com mais precisão e rapidez, pois que tais impropriedades são produtos sedimentados - ou em estado de suspensão - de há muito tempo, das falhas do instrumental administrativo disponivel.

Antes da nova sistemática, a centralização excessiva e a deficiência de programação global dificultavam a boa execução dos projetos ou atividades, já que não possibilitavam um ajustamento entre a disponibilidade financeira e as necessidades técnicas.

A introdução da programação, além dos aspectos positivos já apontados, possibilitou a coordenação e supervisão central, bem como a eliminação de excessos burocráticos.

Por sua vez, a execução financeira foi descentralizada ao mesmo tempo em que se estabeleceram sistemas de acompanhamento e contrôle, os quais continuam apresentando ótimos resultados.

A automaticidade foi alcançada em virtude da preparação antecipada de todo instrumental programático, permitindo grande velocidade na gerência dos recursos. Também a flexibilidade foi atingida à medida em que o sistema propiciou as correções necessárias em nível local, onde efetivamente se processa a execução dos programas. 
O sistema de contrôle vem apresentando resultados positivos, quando 0 comparamos com os mecanismos utilizados anteriormente. Assim, pela primeira vez a nível ministerial, se conseguiu através da contabilidade orçamentária e financeira, o registro de todos os atos e fatos ali processados, possibilitando, ao órgão setorial de contrôle, o conhecimento da execução financeira dos projetos por local de trabalho, desde o Território de Roraima até o Rio Grande do Sul. Isso, graças aos relatórios mensais de acompanhamento, através dos quais se verifica, com apenas 30 dias de defasagem, o comportamento das despesas em cada área de ação do Ministério da Agricultura.

No. campo da Auditoria, que é o elemento auxiliar mais eficiente do sistema de contrôle, a ação da Inspetoria-Geral de Finanças se fêz presente em 1968, em todos os Estados da Federação. Não foi uma auditoria convencional, porém, como primeira etapa, dirigida para o funcionamento do sistema e as implicações da rotina administrativa. A finalidade principal foi o diagnóstico da situação processual em cada área de ação, com vistas às correções das falhas existentes, bem como o comportamento do fluxo dos recursos, no intuito de salvaguardar os princípios de automaticidade, rapidez e flexibilidade, sem afetar o necessário acompanhamento e con-
trôle.

Não obstante o caráter específico que norteou essa primeira fase de auditoria, os seus agentes, nos contatos com os executores e na verificação dos procedimentos locais, levantaram uma série de problemas que, embora estranhos em alguns casos ao sistema financeiro, tinham sua influência negativa sôbre 0 bom funcionamento do mesmo. Verificou-se que os problemas levantados por variáveis estruturais e institucionais não são de fácil e rápida solução.

No momento, encontra-se em execução uma auditoria para exames das tomadas de contas anuais dos ordenadores de despesas e conseqüente expedição dos respectivos certificados.

Ao lado dos auditores contábeis, encontram-se, também, analistas administrativos. Êsses analistas têm a missão de proceder ao levantamento das situações locais, quer no campo da administração financeira, quer no administrativo em geral, visando ao diagnóstico e a uma análise da problemática atual.
Pretende-se partir para o equacionamento das soluções a curto e a médio prazos, em têrmos de correção e como suporte à dinamização do processo administrativo.

Para êsse trabalho conjugado, de auditoria e análise, concentraram-se esforços durante vários meses, no sentido da seleção e treinamento de elementos para a constituição das equipes e para a elaboração de normas e roteiros de ação

Estamos certos de que os resultados
dessa nova etapa, em execução com
maior profundidade, serão os mais po-
sitivos, capacitando melhor o órgão se-
torial do sistema para elaboração de
uma estratégia de ação integrada para
a correção dos vícios e erros, na gerên-
cia da coisa pública e na aplicaçăo dos
recursos financeiros.

Em face do longo perío do de ausência de um contrôle eficiente, espera-se a constatação de uma série de impropriedades na execução orçamentária decorrentes em grande parte da falta de maior velocidade na execução da Reforma Administrativa, especialmente no que se refere à adequação dos meios às funçốes do Govêrno.

Cabe aqui fazer referência a uma premissa constantemente citada pelo Senhor Ministro Ivo Arzua: "O desenvolvimento econômico consiste na eliminação de problemas de ordem inferior e a criação de problemas de ordem superior. $\mathrm{E}$ o desenvolvimento se dará na razão direta da capacidade e rapidez com que solucionamos êstes problemas." Esta premissa pode ser correlacionada com a seguinte: "O desenvolvimento cria problemas, para os quais sòmente o próprio desenvolvimento apresenta soluções."

Nesse contexto, diante da realidade indiscutível, apresenta-se o verdadeiro desafio à nossa capacidade em gerir a coisa pública, como seja a rapidez com que devemos absorver e utilizar os recursos que o desenvolvimento coloca à nossa disposição para a solução dos problemas encontrados.

Passaremos, então, a analisar, especificamente, êsses problemas.

Ressalta-nos, em primeiro plano, a inadequabilidade dos instrumentos técnico-legais e estruturais colocados à disposição dos executores das funções do Govêrno. 
Inegàvelmente, o instrumental técnico-legal não acompanhou a rapidez da evolução da sociedade, ou, quando isto aconteceu, mostrou-se incompatível dentro do contexto global.

A sociedade em seus atributos naturais pressiona e exige a prestação de serviços do Govêrno.

Nesta concepção, os executores dos programas técnicos do Ministério da Agricultura - como agentes propulsores do desenvolvimento - sentem, por um lado, a necessidade de aumentar a sua produtividade, e, por outro lado, as exigências no cumprimento de normas perdidas no binômio tempo-espaço, muitas delas imprecisas e inócuas e que não mais se ajustam às peculiaridades das novas técnicas que se sucedem no processo de desenvolvimento sócio-econômico dos dias atuais.

Sôbre esta última afirmativa, temos a considerar que a Lei n. $0^{4} .320 / 64$, o Decreto-lei n. ${ }^{\circ}$ 200/67 e a Constituição de 1967 trouxeram princípios e conceitos dos mais modernos, porém, muitas vêzes incompatíveis com a realidade sôbre a qual teriam que atuar, e da qual decorriam principios e conceitos diversos. Por sua vez, os documentos legais acima citados, quando tratam do campo de análise, supõem um perfeito funcionamento dos sistemas de planejamento, de pessoal, de material e de serviços gerais, o que não acontece, conforme estamos sentindo com a implantação dos novos sistemas.

Nesse contexto, os executores geralmente têm que adotar uma das opções: ou cumprem suas funções dentro da normalidade técnica, ou atendem às formalidades legais que, por serem inadequadas, geram gargalos e estrangulamentos no processo de execução.

Ainda sôbre a inadequabilidade do instrumental, mesmo quando otimizado, temos a considerar, muitas vêzes, a impossibilidade de seu cumprimento, em virtude de vícios ambienciais e estruturais.

O Serviço Público Federal dispõe de técnicos altamente capazes - no caso do Ministério da Agricultura, engenheiros-agrônomos e veterinários - funcionando no campo da gerência dos recursos financeiros, sem as condiçôes próprias requeridas. $\mathrm{E}$, à medida que se avolumam normas administrativas a cumprir, gerando verdadeiro tumulto, maiores problemas se criam para aquêles téc- nicos, agravados, ainda, pela ineficiência ou inexistência das atividades auxiliares. É necessário ressaltar, também, o número de unidades executoras espalhadas pelo território nacional - postos agropecuários, fazendas-modêlo, estações experimentais e outros - muitas vêzes em pontos longínquos e com precários meios de comunicação, contando com reduzido número de servidores, de um modo geral de baixo nível funcional e de instrução, e que também têm, mesmo que elementarmente, de executar as tarefas atinentes aos sistemas das atividades-meio.

Sôbre as condições ambienciais, temos que encarar também, com o devido realismo, a regra do jôgo vigorante até bem pouco tempo, mas que mantém reflexos negativos no processo administrativo.

Assim, os aspectos conjunturais da política administrativa e as injunções da política partidária; a falta de programação e ausência de contrôle efetivo; a não-assimilação e adoção de técnicas administrativas modernas; a deficiência de estruturas e, finalmente, a inadequação do instrumental disponivel e mal utilizado, no tempo e no espaço, consolidaram erros e vícios, hoje insuperáveis a curto prazo, mas que devem ser, necessàriamente, compreendidos, com vistas às correções graduais e objetivas para a adequação desejada.

Considerando que a implantação dos sistemas de Administração Financeira, Contabilidade e Auditoria sofreu os reflexos dos vícios e erros existentes e sedimentados na administração pública e, considerando-se, também, o não-desenvolvimento, no nível requerido, do processo geral de reforma, os sistemas ainda não puderam cumprir, integralmente, as suas funções. Neste caso, terá que ser restringida sua atuação, a curto prazo, às atividades consideradas básicas, inclusive evitando-se a sua ação imediata na solução de problemas anteriores ao exercício de 1968.

Convém ficar esclarecido e entendido que, à medida que o sistema de contrôle financeiro evolui, cautelosamente, de modo a não permitir os abusos e eliminar, gradativamente, aquêles vícios e erros, êle contribui para a correção do processo administrativo, significando um esfôrço altamente positivo. É que antes do advento do Decreto-lei n. ${ }^{\circ} 200 / 67$, pouco havia sido realizado em matéria de contrôle, muito embora a pletora de leis e normas existentes. 


\section{RSP}

Os mecanismos atuais de contrôle nesta primeira etapa devem servir de instrumentos preventivos e corretivos, objetivando a eficiente aplicação dos dinheiros públicos, evitando a criação de novos problemas e adotando medidas punitivas nos casos comprovadamente dolosos.

Os erros e vícios constatados através dos mecanismos de contrôle da nova sistemática, devem ser analisados e compreendidos em função de suas causas e efeitos, distinguindo-se os de caráter causal cometidos dentro de princípios sadios, dos casos que apresentam indícios de malversação dos dinheiros públicos.

As reformas, em qualquer tempo ou em qualquer área, sempre constituíram exceções, tornando a regra do desenvolvimento uma corrida, cujo aceleramento, em nosso caso, foi disparada com atraso.

Em verdade, para vencermos aquêle retardamento, necessitamos, em têrmos de integração ao contexto desenvolvimentista, de reforma em processo contínuo, cuja escalada deverá se realizar em progressão geométrica de molde a ampliar o potencial existente. 